\title{
Analysis on the Influencing Factors of Farmers' Willingness to Scale Operation
}

\author{
Xiao Rong \\ School of Economics and Management, Zhejiang Agriculture and Forestry University, Hangzhou, China \\ Email:1183379787@qq.com
}

How to cite this paper: Rong, X. (2021). Analysis on the Influencing Factors of Farmers' Willingness to Scale Operation. Open Journal of Social Sciences, 9, 1-11. https://doi.org/10.4236/jss.2021.98001

Received: June 25, 2021

Accepted: July 27, 2021

Published: July 30, 2021

Copyright (c) 2021 by author(s) and Scientific Research Publishing Inc. This work is licensed under the Creative Commons Attribution International License (CC BY 4.0).

http://creativecommons.org/licenses/by/4.0/

\begin{abstract}
At present, the land fragmentation caused by small-scale production and management of farmers restricts the promotion of agricultural modernization in China. In response to the national rural revitalization strategy, it is the current trend of agricultural development to build a new socialist countryside with strong agriculture, beautiful rural areas and rich farmers, and to encourage small-scale farmers to operate in an appropriate scale. In this context, this study took 326 households of farmers in Zhejiang province as samples, and adopted binary logistic model to analyze the influencing factors of farmers' land scale management intention, so as to explore ways to improve farmers' scale management intention. The results show that three important factors, distance from the nearest agricultural trade market, planting years and agricultural technology training, have a significant impact on the willingness of farmers to operate on a large scale, and accordingly, corresponding policy suggestions are put forward to promote the promotion of agricultural scale.
\end{abstract}

\section{Keywords}

Fragmentation, Scale Operation of Land, Moderate Scale, Factors Affecting

\section{Introduction}

The small-scale production and management of farmers is one of the important issues restricting the development of my country's agriculture. With the development of my country's economy in recent years, the continuous advancement of industrialization and urbanization, the lack of agricultural development has gradually emerged, which has become an important factor restricting my country's economic development. Since 2004, the Central Committee's No. 1 Document has focused on the "three rural issues" for 16 consecutive times. The 19th 
National Congress also proposed a rural revitalization strategy to promote my country's agricultural development. The issue of agricultural development brooks no delay. The issue of agriculture and rural farmers is a fundamental issue related to the national economy and people's livelihood. According to the report of the 19th National Congress of the Communist Party of China, the overall requirements for the development of agriculture and rural areas should be prioritized from the five aspects of industrial prosperity, ecological livability, rural civilization, effective governance, and affluent life. The ultimate goal of development is the prosperity of farmers' lives. At present, my country's agricultural development is facing bottlenecks, and it is difficult to advance agricultural modernization. The core problem is that my country's agricultural production and operation are still dominated by small-scale decentralized farmers, and the problem of low production efficiency is difficult to solve. Therefore, moderate scale management is the current trend of my country's agricultural development $(\mathrm{Li}$, 2015; Wei, 2014). Through moderate scale operation of agricultural production, production and operation costs can be reduced, production efficiency can be improved, and farmers can obtain scale returns and increase farmers' income. Encouraging small-scale farmers to develop into large-scale farmers and farmers is the main direction of the current development of agricultural modernization in my country, and it is also the focus of the implementation of the rural revitalization strategy (Wang, 2018).

At present, the further development of agriculture is mainly realized by relying on the innovation of agricultural production technology and the reduction of production and operation costs. By increasing the output of agricultural products or saving production and operation costs, we can obtain greater profit margins and promote farmers' income. At present, the level of my country's agricultural technology has been significantly improved compared to the past, and there is not much room for improvement, but for small-scale farmers, it is still difficult to implement new technologies. Therefore, the problem of how to save production and operation costs has become particularly prominent, and has become an important factor restricting the current agricultural development. Therefore, in order to solve the problem of high production and operation costs for small-scale farmers in our country, it is necessary to solve the problems of land decentralization and small-scale operation, that is, to promote the scale operation of farmers (Ling, 2014) and use the scale brought by moderate scale operation. Benefit, reduce production and operation costs, increase profit margins of agricultural products, and then increase farmers' incomes, and promote the new development of modern agriculture in my country. However, in the current process of my country's promotion of scale, the willingness of farmers to scale operations may be affected by many factors such as internal factors such as individual characteristics of farmers, external factors such as the level of economic systems, and constraints and changes in production decision-making in production and management (Yang et al., 2019). Therefore, we need to study the in- 
fluencing factors of the farmers' willingness to scale operation, and determine how each factor will affect the farmers' willingness to scale operation, and to what extent?

Academia has conducted extensive discussions and studies on the influencing factors of farmer's land scale management. From the perspective of economic policies and other external factors, the relevant policies and systems of scale operation are inconsistent with the farmers' business objectives in terms of objectives, which make the system unable to integrate well with the farmers' own production and management (Peng, 2009) and restrict the development of scale operations. Therefore, the formulation of the system should take into account the farmers' own business objectives. Some scholars advocate the use of relevant land transfer policies to encourage small-scale farmers to transfer land management rights to promote large-scale advancement (Chen \& Su, 2017; Yao, 2000; Liao et al., 2011; Jiang \& Xi, 2014). Some scholars believe that perfecting the social service function of agriculture can also promote the large-scale development of agriculture (Yang et al., 2019; Kong \& Mu, 2018), and the large-scale service can drive the large-scale land to a certain extent. From the perspective of internal management factors of farmers, the political status of farmers and rural social security can promote the transfer of land management rights (Fu \& Chen, 2017; Yan \& Huo, 2013), which provides a prerequisite for the advancement of scale; and agricultural skills training can improve the quality of farmers and make them Transform to modern professional farmers, improve the willingness of farmers to scale operation (Zheng \& Luo, 2020), and guide farmers to scale production and operation; the financing ability of farmers themselves can solve the worries of funds for the expansion of scale operation of farmers, and has a direct impact on the willingness of farmers to scale operation (Zhao \& Yue, 2017). In addition, the management concept of farmers (Xu, 2013; Ma et al., 2015; He, 2016) and the situation of concurrent occupation (Zhang \& Qian, 2014; Gao, 1995; Xiao \& Qi, 2014; Huang, 2012) also have an important impact on the willingness of farmers to scale operations. In view of the characteristics of high social effects and low self-effects of agriculture, agriculture has become a weak industry in my country's economic development. Farmers are more willing to engage in non-agricultural work with higher returns (Xu, 2013), but are not very enthusiastic about agricultural production and management, so they cannot Concentrate and professionally engage in agricultural production (Ma et al., 2015; $\mathrm{He}, 2016)$. This has also directly led to the prevalence of part-time operations in rural areas in my country. The non-agricultural part-time income of rural households accounts for a relatively high proportion of the total family income (Xiao \& Qi, 2014), but it is also due to the basic role of agricultural income and the positive significance of land preservation, making farmers unwilling to give up farmland, leading to restrictions on the advancement of land scale.

In summary, the existing studies are mostly based on external factors such as economic policies and the political background of farmers (Fu \& Chen, 2017), social security background (Yan \& Huo, 2013), part-time background (Zhang \& 
Qian, 2014; Gao, 1995; Xiao \& Qi, 2014; Huang, 2012) and agricultural socialized services (Yang et al., 2019) to analyze the correctness There are relatively few studies on the impact of land scale management on the impact of farmers' individual family characteristics and other micro-level analysis on the impact of farmers' willingness to scale management. Therefore, this study will start from this aspect, and further improve the research on the factors affecting the willingness of farmers to scale operation. Using a combination of theory and empirical research, qualitative and quantitative research methods, taking 326 farmer households in Zhejiang Province as the research sample, using a binary logistic model to analyze the influence and degree of influence of individual characteristics of farmer households on the willingness of farmer households to scale operation, and for related research The conclusion puts forward relevant policy recommendations that help increase farmers' willingness to scale operation.

\section{Research Hypotheses, Data Sources and Model Settings}

\subsection{Variable Selection and Hypothesis}

According to the combing of relevant literature and the theory of farmer's production behavior, the number of farmer households' labor force, the educational level of the farmer's head, the distance from the farmer's family to the nearest agricultural product trade market, the current planting scale of the farmer's household, the number of years of business, and the number of people trained in agricultural technology by the farmer household are The representative of measuring the individual characteristics of rural households is an important indicator for studying the scale operation of rural households from a micro perspective. Therefore, this paper selects the above 6 indicators as the characteristics of individual rural households to study their influence on the willingness of rural households to scale operation, and do it according to related theories. Make the following assumptions:

1) The number of labor force of rural households has a positive impact on the willingness of rural households to scale land management. The more labor in the farm household, the more potential labor in the farm household that may be engaged in agricultural production and operation, and the stronger the willingness of the farm household to expand the scale of land operation;

2) The educational level of the head of the farmer household has a positive influence on the willingness of the farmer's land scale operation. With the country's emphasis on agriculture in recent years and the impact of large-scale propaganda, the more educated farmers are, the more knowledge they have gained, and the more they understand the relevant theories and policies of large-scale operations, which makes them easier to accept. Respond to policy propaganda, and thus expand the scale of land operation, and the willingness to earn scale returns may be stronger;

3) The distance between the farmer family and the agricultural product trade 
market has a negative impact on the farmer's willingness to scale land management. The closer the farmer's family is to the agricultural product trade market, the lower the transportation cost the farmer has to pay when transporting agricultural products, and the greater the profit margin that the farmer can obtain. Therefore, the stronger the willingness of the farmer to scale the operation of land may be;

4) The current planting scale of farmers has a significant impact on the willingness of farmers to scale their land, but the direction is uncertain. For smallscale farmers, the larger the planting scale and the closer to the appropriate scale, the more returns to scale the farmers earn, and the stronger the willingness of farmers to scale land management; but for some farmers that have reached or exceeded the appropriate scale, The larger the planting scale, the lower the return to scale. Therefore, the willingness of these farmers to scale land management may not be strong, and may even be weakened;

5) The operation period of farmers has a significant impact on the willingness of farmers to scale their land, but the direction is uncertain. The longer the farmer's operating period, the more agricultural-related experience the farmer has accumulated, and the more confident the farmer will be in the scale of land management, and therefore the stronger their willingness to scale the land; but it is also possible that the longer the farmer's operating period will be , The deeper the reliance on experience, the more solidified the thinking, the worse the acceptance of new things, so it may be more willing to accept traditional management methods, but the willingness to scale land management is not strong;

6) The number of farmer households trained in agricultural technology has a positive impact on the farmers' willingness to scale land management. To a certain extent, farmers' families receive more agricultural technology training, which means that farmers' professional capabilities are stronger, and they have more technical guarantees for land scale management. Therefore, farmers' willingness to scale land management is also stronger.

In this paper, stata 15 is used to construct a logit model to perform regression analysis on the number of rural household labor force, the educational level of the household head, the distance between the household and the nearest agricultural product trade market, the current planting scale of the household, the number of years of business, and the number of times the household has received agricultural technology training. To verify the significance of the above indicators on the willingness of farmers to scale operations. In the regression results, if the $p$-value is less than 0.01 , then this indicator is significant at the $1 \%$ significance level of farmers' willingness to scale land management; if the $p$-value is between 0.01 and 0.05 , then this indicator is significant to farmers' willingness to scale land management Significant at the $5 \%$ level of significance; if the $p$-value is between 0.05 and 0.1 , then this indicator is significant at the $10 \%$ significance level for the farmers' willingness to scale land management; if the $p$-value is greater than 0.1 , the indicator is The farmers' willingness to scale land 
management has no significant impact.

\subsection{Data Sources}

The data used in this article is from July-August 2015 on household surveys of rural households in Songyang County, Suichang County, Lin'an District, and Shangyu District of Shaoxing City in Zhejiang Province. Based on the development of rural areas in Zhejiang Province, this survey selected 4 regions of Songyang County, Suichang County, Lin'an District and Shangyu District from the low, medium, and high three dimensions of rural development to conduct a questionnaire survey. The questionnaire comes from Zhejiang Agriculture and Forestry University. In the survey database, a total of 400 questionnaires for farmers were issued. After excluding invalid questionnaires, a total of 326 questionnaires were obtained. The effective rate of the questionnaires was $81.5 \%$. The survey obtained relevant data through random sampling in the above-mentioned counties, and its contents included: the status of farm households receiving agricultural technology training, the amount of labor input of the farm households, the current planting scale of the farm households, and the distance between the farm households and the nearest agricultural product trade market. After sorting out the questionnaires and eliminating invalid questionnaires, this paper finally selected 326 farmers as the research sample.

\subsection{Model Setting}

This study uses a binary logistic model to reflect the farmers' willingness to scale operations with two levels of "willing" and "unwilling". 1 means willing, 0 means unwilling, and defines farmers who are only willing to stabilize the scale, reduce the scale, and withdraw from production. For farmers who are unwilling to operate on a scale of land, the farmers who are willing to expand production are defined as farmers who are willing to operate on a scale of land. Set Y farmer households' willingness to scale operation (willing or unwilling) as the explained variable, $\mathrm{x} 1$ family labor input, $\mathrm{x} 2$ household head's education level, $\mathrm{x} 3$ distance from farmer's home to the nearest agricultural product trade market, $\mathrm{x} 4$ existing farmland planting scale, $x 5$ Six variables including the length of planting and the number of people trained in agricultural technology for $\mathrm{x} 6$ families are explanatory variables. Establish the following binary logistic model:

$$
\log \text { istic }\left(p_{i}\right)=\log \left(\frac{p_{i}}{1-p_{i}}\right)=\eta_{i}
$$

In the (1), $p_{i}$ represents the willingness of farmers to expand the scale of land management, and $1-p_{i}$ represents the willingness of farmers to expand the scale of land management. Furthermore, formula (1) can be expressed as a linear combination of a set of independent variables:

$$
\log \operatorname{istic}\left(p_{i}\right)=\eta_{i}=\sum_{k=0}^{K} \beta_{k} x_{i k}
$$


Then linearly calculate the Equation (2) to get:

$$
p_{i}=\frac{\exp \left(\sum_{k=0}^{K} \beta_{k} x_{i k}\right)}{1+\exp \left(\sum_{k=0}^{K} \beta_{k} x_{i k}\right)}
$$

\section{Empirical Research}

\subsection{Descriptive Statistical Analysis}

From Table 1, we can analyze and get the following information:

Among the 326 households surveyed, the number of household labor force of the households is generally controlled between 1 - 16 people. On average, there are about 2 to 3 people in each household who can be used for agricultural production and operation; the education level of each household head is mainly concentrated in elementary school to At the junior high school level, there is a lack of high-quality talents in the development of agricultural production and management; the distance between the family and the nearest agricultural product trade market ranges from 0.03 kilometers to 150 kilometers. The settlement of farmers is relatively scattered, which shows that the land fragmentation is serious.; The current planting scale of each farmer household is about $42.6 \mathrm{mu}$ on average, the large farmer reaches $950 \mathrm{mu}$, and the small farmer is only $1 \mathrm{mu}$. The planting scale varies greatly among farmer households; the average planting period of each farmer household is about 11 years, but the shortest Farmers only plant for one year, and the longest can be up to 45 years; the average number of people trained in agricultural technology for each farmer family is about one to two people, and the agricultural technology training for farmer families still needs to be improved.

\subsection{Model Estimation Results and Analysis}

Regression analysis of the above data model with Stata software can be obtained:

It can be seen from Table 2 :

1) The distance between farmer households and the nearest agricultural product trade market has a significant positive impact on farmer households'

Table 1. Descriptive statistics of various factors that affect farmers' willingness to scale operation.

\begin{tabular}{|c|c|c|c|c|c|}
\hline Variable name & Unit of measurement unit & Mean & Dev. & Min & $\operatorname{Max}$ \\
\hline Number of family labor force & nos & 2.75 & 1.18 & 1 & 16 \\
\hline $\begin{array}{l}\text { Educational level of } \\
\text { head of household }\end{array}$ & $\begin{array}{l}1 \text { illiterate; } 2 \text { elementary school; } 3 \text { junior high school; } 4 \text { high school } \\
\text { and technical secondary school; } 5 \text { junior college and above }\end{array}$ & 2.83 & 0.84 & 1 & 5 \\
\hline $\begin{array}{l}\text { The distance from the family to the } \\
\text { nearest agricultural trade market }\end{array}$ & Kilometers & 10.10 & 17.15 & 0.03 & 150 \\
\hline Existing tea planting scale & $\mathrm{mu}$ & 42.60 & 114.52 & 1 & 950 \\
\hline Planting years & years & 11.87 & 7.69 & 1 & 45 \\
\hline $\begin{array}{l}\text { Number of households trained } \\
\text { in agricultural technology }\end{array}$ & nos & 1.22 & 2.01 & 0.0 & 16 \\
\hline
\end{tabular}


Table 2. Logistic regression of factors affecting farmers' willingness to scale operation.

\begin{tabular}{lllll}
\hline & Coef. & Std. Err. & $\mathrm{z}$ & $p>|\mathrm{z}|$ \\
\hline Number of family labor force $(\mathrm{x} 1)$ & 0.1454768 & 0.13091 & 1.11 & 0.266 \\
Educational level of head of household $(\mathrm{x} 2)$ & 0.1643735 & 0.1917291 & 0.86 & 0.391 \\
The distance from the family to the nearest agricultural trade market $(\mathrm{x} 3)$ & $0.012789^{*}$ & 0.0073172 & 1.75 & 0.080 \\
Existing tea planting scale $(\mathrm{x} 4)$ & 0.0008861 & 0.0011469 & 0.77 & 0.440 \\
Planting years (x5) & $-0.0499294^{* *}$ & 0.0233296 & -2.14 & 0.032 \\
Number of households trained in agricultural technology (x6) & $0.2476352^{* *}$ & 0.0704413 & 3.52 & 0.000 \\
\hline
\end{tabular}

${ }^{\star}$ Represents that the variable is significant at a significance level of $10 \%$; ${ }^{* *}$ represents that the variable is significant at a significance level of $5 \%$; ${ }^{* * *}$ represents that the variable is significant at a significance level of $1 \%$.

willingness to scale operation at a significant level of $10 \%$, which is inconsistent with the hypothesis. The reason for this result may be that the land price factor of land circulation was not considered. According to the land price theory, the farther away from the city center, the lower the land price. In rural areas, the agricultural product trading market belongs to the central area. The farther the farmer's family is from the agricultural product trading market, the lower the land price during land transfer. This reduces the expansion cost of the farmer's land scale operation and increases the profit of the farmer's production and operation. space. That is, the farther the farmer's family is from the nearest agricultural product trade market, the stronger the farmer's willingness to scale the land.

2) The planting period of farmers has a significant positive impact on the willingness of farmers to scale operations at a significant level of 5\%, which is consistent with the hypothesis. That is to say, the longer the farming period, the stronger the willingness of the farmer to scale the land.

3) The number of farmer households trained in agricultural technology has a significant positive impact on the willingness of farmer households to scale operations at a significant level of $1 \%$, which is consistent with the hypothesis. That is, the more farmers' families receive agricultural technology training, the stronger their willingness to scale land management.

4) The number of rural households' labor force has no significant effect on the willingness of rural households to scale operations, which is inconsistent with the hypothesis. The reason for this result may be the more serious part-time workforce of rural households, which leads to the fact that although there are more labors in rural households, there are not many labors engaged in agricultural production and operation.

5) The educational level of the head of the farmer household has no significant impact on the willingness of farmer households to scale operation, which is inconsistent with the assumption. The reason for this result may be that the heads of rural households are generally of a certain age, and their education levels are mostly concentrated in elementary and junior high school education, so they cannot affect the willingness of farmers to scale operations; it may also be that 
the households actually engaged in agricultural production and management work are not The head of the household, therefore, the education level of the head of the household cannot directly affect agricultural production and operation.

6) The current planting scale of farmers has no significant impact on the willingness of farmers to scale operation, which is inconsistent with the assumption. The reason may be due to the unequal current planting scale of each farmer. For farmers who have a certain scale of operation but have not reached the critical point of scale benefits brought about by scale operations, since continuing to expand scale operations can obtain greater scale benefits for them, such farmers have a strong willingness to scale operations; but they have reached the scale of planting. Or farmers with more than a moderate scale, because their business scale exceeds the critical point of obtaining scale benefits, their profit margins are reduced, so their willingness to expand the scale of land management is not strong. However, small-scale farmers may be restricted by factors such as capital and technology, and their willingness to scale operations may not be strong. Therefore, the impact of the farmers' current planting scale on the farmers' willingness to scale operation needs to be determined by the specific circumstances of whether the existing scale has reached an appropriate scale.

\section{Conclusion and Policy Recommendations}

To sum up: Through the analysis of empirical results, the following conclusions can be drawn: 1) The promotion of land scale management should choose to be far away from the agricultural product trade market area. The family residence of farmers often determines the location of their land. Land far away from the agricultural product trade market has the characteristics of low land prices, which can greatly reduce the cost of land transfer by farmers during the expansion of land scale management, thereby inspiring farmers' willingness to scale management; 2) The preferred target for the promotion of land scale management should be farmers with a certain number of planting years. The longer the farmer's planting years and the richer the experience, the more mature the agricultural production technology and the more able to undertake the practice of large-scale operation; 3) Agricultural technology training has important guiding significance for the large-scale operation of farmers' land. Through agricultural technology training, it is possible to effectively strengthen farmers' learning of relevant agricultural technologies and understanding of agricultural policies, and enhance farmers' confidence in large-scale operations.

Policy recommendations: In order to adapt to the development trend of agricultural modernization, to further promote the new development of my country's agriculture, to make agriculture a promising industry, to achieve the great goal of strong agriculture, beautiful rural areas, and rich farmers, large-scale agricultural operation is the general trend. This research aims at how to strengthen the willingness of farmers to scale land management, and then promote the 
process of land scale in my country, promote the development of rural economy, and improve the problems of agriculture, rural areas and farmers. The following suggestions are made:

1) The local government should actively encourage farmers who are willing to expand the scale of land operations to select land away from the agricultural product trade market for land transfer, and provide relevant preferential policies. Such areas are far away from populated areas, have low land prices, and are not easily affected by human factors (living pollution, trampling, etc.), making them the first choice for farmland management. It can reduce the contracting costs of farmers and increase profit margins without affecting rural construction and development;

2) The local government should strengthen the assessment mechanism of subsidies for the length of planting period of farmers. Higher subsidies are given to farmers who have been engaged in agricultural production for many years, and the subsidy ratio is determined according to the farming years of the farmers. Make farmers more motivated to engage in agricultural production and operation, firmly attract capable people to agriculture, and reduce the weakening effect of part-time operation on the willingness of land scale operation. Only by ensuring the long-term planting period, can the farmers' willingness to scale operation not decline;

3) The local government should vigorously organize relevant agricultural technology training to provide a sufficient base of reserve talents for the villages. Cultivate a new type of professional farmers who understand agriculture, know technology, and are good at management, and improve the current poor cultural quality of agricultural workers. Through the improvement of the quality of personnel, the development of agricultural specialization and large-scale development will be promoted, and agricultural modernization will be promoted.

\section{Conflicts of Interest}

The author declares no conflicts of interest regarding the publication of this paper.

\section{References}

Chen, J., \& Su, Q. (2017). Land Circulation, Land Productivity and Scale Management. Agricultural Technology and Economy, No. 1, 28-36.

Fu, Z. Q., \& Chen, S. Y. (2017). Does Political Status Affect Farmers' Willingness and Behavior to Transfer Land Management Rights?-Analysis Based on Survey Data of 3305 Farmers in 28 Provinces. China Rural Observation, No. 5, 130-144.

Gao, Q. (1995). Analysis on the Concurrent Business Operation of Farmer HouseholdsReflections on Farmer Households' Management in Northwest China. Economic Issues, No. 5, 20-23.

He, X. R. (2016). Thoughts on the Scale of Agricultural Operations in My Country. Issues in Agricultural Economy, 37, 4-15.

Huang, Y. T. (2012). Analysis of the Restriction Mechanism of Concurrent Farming on 
Farmland Scale Management. Rural Economy, No. 1, 49-51.

Jiang, C. Y., \& Xi, K. Y. (2014). Thoughts on Guiding Rural Land Circulation to Develop Agricultural Scale Management. Jianghuai Forum, No. 4, 61-66.

Kong, X. Z., \& Mu, N. N. (2018). Realize the Organic Connection between Small Farmers and Modern Agricultural Development. Rural Economy, No. 2, 1-7.

Li, R. Q. (2015). Cultivated Land Availability, Scale Management and Farmers' Income from Field Planting. Macroeconomic Research, No. 1, 95-102, 108.

Liao, X. Y., Shen, H. F., \& Wang, Z. G. (2011). The “Three Steps" Strategy of Agricultural Scale Operation with Chinese Characteristics-From "Circulation of Production Links" to "Circulation of Management Rights" to "Circulation of Contracting Rights". Issues in Agricultural Economy, 35, 15-22.

Ling, S. (2014). The Willingness of Farmer Households to Scale Management and Its Influencing Factors: Reflections Based on a Sample Questionnaire Survey in 26 Provinces and Regions across the Country. Rural Economy, No. 4, 96-100.

Ma, T. T., Chen, Y., \& Song, W. (2015). Research on the Impact of Farmers' Land Awareness on Farmland Transfer and Scale Management Willingness: Taking Wuwei City, Gansu Province as an Example. Arid Land Resources and Environment, 29, 26-32.

Peng, K. Q. (2009). Co-Integration Analysis of China's Grain Production Income and Its Influencing Factors: Taking Rice, Wheat and Corn as Examples from 1984 to 2007. China Rural Economy, No. 6, 13-26.

Wang, J. Y., \& Wang, C. Y. (2018). Agricultural Scale Operation: The Focus of Rural Revitalization Strategy. Chinese Administration, No. 4, 91-97.

Wei, X. S. (2014). The Practice and Enlightenment of the United States to Promote the Scale of Agricultural Production and Operation. Economic Aspects, No. 12, 73-76.

Xiao, E., \& Qi, C. J. (2014). Analysis of the Willingness and Influencing Factors of Farm Household Farm Management in my Country. Business Research, No. 11, 106-111.

$\mathrm{Xu}$, M. Y. (2013). Farmer Class Differentiation, Property Rights Preference Difference and Land Transfer Willingness-Based on the Empirical Analysis of 387 Farmer Households in Taizhou City, Jiangsu Province. Social Sciences, No. 1, 56-66.

Yan, X. H., \& Huo, X. X. (2013). Farmer Employment, Rural Social Security and Land Transfer: Analysis Based on the Survey of 479 Farmer Households in Henan Province. Agricultural Technology and Economy, No. 7, 34-44.

Yang, Z., Rao, F. P., \& Zhu, P. X. (2019). The Impact of Agricultural Socialization Services on Land Scale Management: An Empirical Analysis Based on the Perspective of Farmers' Land Transfer. China Rural Economy, No. 3, 82-95.

Yao, Y. (2000). China's Agricultural Land System: An Analysis Framework. Chinese Social Sciences, No. 2, 54-65, 206.

Zhang, Z. M., \& Qian, W. R. (2014). Research on Farmers' Land Circulation Willingness under Different Part-Time Levels-Based on Investigation and Empirical Research in Zhejiang. Issues in Agricultural Economics, 35, 19-24+110 .

Zhao, J. G., \& Yue, S. M. (2017). Analysis on the Influencing Factors of Farmers' Willingness to Scale Management. Shandong Social Sciences, No. 1, 116-121.

Zheng, Y. Y., \& Luo, J. L. (2020). Can Agricultural Production Training Increase Farmers' Willingness to Expand Farmland?-Evidence from 2340 Farmers in 12 Provinces. Journal of Huazhong Agricultural University (Social Science Edition), No. 2, 39-48, 163-164. 